\title{
O DESAFIO DOS PROFESSORES DE DIREITO EM TEMPOS DE MODERNIDADE LÍQUIDA
}

\author{
THE CHALLENGE OF LAW'S TEACHERS IN LIQUIDI MODERNITY
}

\section{Resumo}

Partindo de uma observação da postura dos alunos da graduação no Direito, chegamos a uma triste constatação: muitos deles se utilizam de fontes cada vez mais fragmentadas e superficiais no seu estudo, fomentados pelo avanço de tecnologias como Iphones e redes e sociais. Ademais, preferem aulas exclusivamente expositivas, que não se voltam para o diálogo com os alunos e o desenvolvimento de sua capacidade argumentativa. O sociólogo Bauman (2008) denomina tal contexto como a "modernidade líquida". Ocorre que o Direito, mais do que qualquer ciência, reivindica bacharéis engajados, com consciência política e conhecimento estruturado. Para resgatar nossos estudantes dessa postura passiva e alienada provocada pela modernidade líquida, os professores, egressos da pós-graduação e extensão universitária, são a chave para desenvolver nos alunos uma aprendizagem efetivamente relevante.

Palavras-chave: Aprendizagem jurídica. Professores de Direito. Modernidade Líquida.

\begin{abstract}
Observing the graduate students in law, we came to a sad conclusion: many of them use sources increasingly fragmented and superficial in their study, promoted by the advancement of technologies such as Iphones and social networks. Moreover, they prefer classes exclusively expository, which do not turn to dialogue with students and developing their capacity to argue. The sociologist Bauman (2008) calls this context as "liquid modernity". That occurs the law, more than any science, claims bachelors engaged, politically aware and structured knowledge. To redeem our students from this passive stance and alienated caused by liquid modernity, teachers - graduates and post-graduate university extension - are the key to develop in students a learning effectively relevant.
\end{abstract}

Keywords: Learning legal. Law’s professors. Liquid Modernity. 


\section{INTRODUÇÃO}

A pós-graduação e a extensão universitária, no segmento jurídico, trazem, em linhas gerais, dois propósitos imediatos: fomentar o estudo aprofundado e a pesquisa de temas; e formar profissionais do Direito capacitados para ensinar àqueles que estão na graduação. Sendo assim, é de suma relevância que os professores de Direito estejam sempre atentos às suas práticas dentro de sala de aula, considerando o contexto em que os seus alunos estão inseridos: a modernidade líquida.

A tarefa de ministrar aulas nos cursos de Direito tem se deparado com um grande desafio: a invasão das salas de aula pelos Iphones, Ipads, celulares, notebooks e similares. Os vade mecuns e livros de doutrina muitas vezes disputam espaço com resumos e cadernos compartilhados pela internet, sem falar na utilização de tais tecnologias durante a aula, para assuntos totalmente alheios à ciência jurídica. Eis a modernidade líquida, tratada pelo sociólogo polonês Zygmunt Bauman (2008).

Tal cenário enseja fundamental reflexão pela academia, pois a busca dos jovens pela tecnologia e pela informação superficial e fragmentada é algo crescente. Nesse cenário, é necessário que os professores assumam seu papel fundamental, buscando alternativas e limites à tecnologia na aprendizagem jurídica.

O professor não deve compreender sua função como a de simplesmente tratar sobre determinados assuntos dentro de sala de aula, ainda que seus alunos assumam uma posição passiva e desinteressada. Ao contrário, é fundamental que os graduandos sejam a todo tempo inseridos dentro dos temas da aula, instigados a aprofundar seus conhecimentos de modo autônomo.

Nesse cenário, veremos como os avanços tecnológicos, em tempos de modernidade líquida, poderiam ser abordados dentro das turmas de Direito, sem prejudicar o conhecimento aprofundado de nossos alunos.

\section{A MODERNIDADE LÍQUIDA INVADE AS TURMAS DE DIREITO}


De acordo Bauman (2008), vivemos a era da modernidade líquida, momento em que o Homem busca sua satisfação de modo cada vez mais egoísta e solitário. Os desejos do Homem pós-moderno são na maior parte das vezes ligados ao consumo, sendo inclusive seus relacionamentos humanos transformados em mercadorias descartáveis, firmados de modo efêmero, frágil e passageiro. Tal cenário se formou em virtude de diversos fatores que podem resumir-se ao fato de o capitalismo ter invadido a vida humana de forma avassaladora,

\begin{abstract}
A instabilidade dos desejos e a insaciabilidade das necessidades, assim como a resultante tendência ao consumo instantâneo e à remoção, também instantânea, de seus objetos, harmonizam-se bem com a nova liquidez do ambiente em que as atividades existenciais foram inscritas e tendem a ser conduzidas no futuro previsível. Um ambiente líquido-moderno é inóspito ao planejamento, investimento e armazenamento a longo prazo. De fato, ele tira do adiamento da satisfação seu antigo sentido de prudência, circunspecção e, acima de tudo razoabilidade. (BAUMAN, 2008, p.45)
\end{abstract}

Nesse contexto, a cultura do diálogo cede espaço ao desenvolvimento de atitudes solitárias dos indivíduos, o que é plenamente fomentado pelo desenvolvimento de tecnologias que lastreiam a formação de "redes" em detrimento da formação de "laços",

\begin{abstract}
Diferentemente de 'relações', 'parentescos', 'parcerias' e noções similares - que ressaltam o engajamento mútuo ao mesmo tempo em que silenciosamente excluem ou omitem o seu oposto, a falta de compromisso -, uma 'rede' serve de matriz tanto para conectar quanto para desconectar; não é possível imaginá-la sem as duas possibilidades. Na rede, elas são escolhas igualmente legítimas, gozam do mesmo status e tem importância idêntica. (...) Elas são 'relações virtuais'. (BAUMAN, 2004, p.11)
\end{abstract}

Voltando nosso olhar para o ambiente acadêmico, especificamente nas faculdades de Direito, veremos que é indiscutível que a modernidade líquida está presente no comportamento de grande parte dos alunos.

Teoricamente, a sala de aula deveria figurar como um espaço para o diálogo e o debate,

A situação de ensino em sala de aula pode ser descrita como um encontro, repetido durante espaços de tempo predeterminados (de 50 minutos a 4 ou 5 horas), com uma frequência (geralmente semanal) igualmente predeterminada e durante um período relativamente longo (semestre ou ano letivo); nesse encontro, seres vivos, seres humanos, confinados dentro dos limites da classe, se defrontam, se comunicam, se influenciam mutuamente. (ABREU, 1990, p.113) 
Ocorre que, infelizmente, nota-se que os alunos têm assumido, cada vez mais, uma postura passiva, evitando a comunicação com seus colegas e professor,

\begin{abstract}
“(...) os estudantes, de acordo com estudos feitos, estão condicionados a ter um tipo de expectativa em relação ao professor. Em geral, ela se encaminha para que o professor fale, "dê aula", enquanto ele, o aluno, escuta e intervém quando acha necessário. O fato de se achar na condição de ouvinte é confortável ao aluno, especialmente se o professor possuir habilidades de ensino que fazem com que a aula não se torne maçante" (CUNHA, 1989, P.136).
\end{abstract}

Nesse cenário, os alunos se sentem desconfortáveis ao serem chamados a participar da aula, a se posicionar e dialogar. Paralelamente, os futuros bacharéis muitas vezes dispensam a leitura, fundamental à sua formação jurídica, atendo-se a resumos e outros materiais circulados pela rede, extremamente fragmentados e superficiais.

Em que pese a gama de ferramentas que os meios tecnológicos proporcionam àquele que pretende estudar, há estudantes que preferem utilizar-se da tecnologia para fragmentar o conhecimento de determinado assunto, tornando-o cada vez mais superficial. O aluno, dessa forma, perde também a sua individualidade, já que deixa de se ater às fontes originais, para buscar resumos construídos por outros autores.

Sobre essa superficialidade do conhecimento, Bauman bem coloca,

Objetos hoje recomendados como úteis e indispensáveis tendem a "virar coisa do passado" muito antes de terem tempo de se estabelecer e se transformar em necessidade ou hábito. Nada é visto como estando aqui para sempre, nada parece insubstituível. Tudo nasce com a marca da morte iminente e emerge da linha de produção com o "prazo de validade" impresso ou presumido. (BAUMAN, 2013, P.22)

O professor, nesse momento, deve incentivar o desenvolvimento individual de seus alunos,

(...) o bom professor é o que consegue enquanto fala, trazer o aluno até a intimidade do movimento de seu pensamento. Sua aula é assim um desafio e não uma "cantiga de ninar". Seus alunos cansam, não dormem. Cansam porque acompanham as idas e vindas de seu pensamento, surpreendem suas pausas, suas dúvidas, suas incertezas." (FREIRE, 1999. P.96)

Nesse sentido, Cunha também nos traz, como principais características positivas dos professores, o envolvimento total dos alunos, provocado pelo mestre, 
(...) entre as características dos melhores professores estão: "torna as aulas atraentes", "estimula a participação do aluno", "sabe se expressar de forma que todos entendam", "induz à crítica, à curiosidade, à pesquisa", "procura formas inovadoras de desenvolver a aula", "faz o aluno participar do ensino" etc.". (CUNHA, 1989. P.71)

Ora, para que um indivíduo se torne bacharel em Direito, é fundamental que seja desenvolvida sua capacidade de argumentação, debate e diálogo com outros pontos de vista. Mas, a modernidade líquida - com seus Iphones, notebooks e outros, distancia os alunos de seu professor e do ambiente do diálogo,

Um encontro face a face exige o tipo de habilidade social que pode inexistir ou se
mostrar inadequado em certas pessoas, e um diálogo sempre significa se expor ao
desconhecido: é como se tornar refém do destino. É tão mais reconfortante saber que
é a minha mão, só ela, que segura o mouse e o meu dedo, apenas ele, que repousa
sobre o botão. (...) Faz sentido, portanto, imitar o suposto hábito do avestruz de
enterrar a cabeça na areia e desviar ou baixar os olhos. Não olhando o outro nos
olhos, torno meu eu interior (para ser mais exato, meus pensamentos e emoções mais
íntimos) invisível, inescrutável... Agora, na era dos desktops, laptops, dispositivos
eletrônicos e celulares que cabem na palma da mão, a maioria de nós tem uma
quantidade mais do que suficiente de areia para enterrar a cabeça. (BAUMAN, 2008,
p.27).

Além disso, a capacidade crítica dos nossos alunos de Direito tem se perdido. Vemos uma juventude que busca informar-se de modo fragmentado, sem a construção de um pensamento político crítico dentro do Estado Democrático de Direito em que vive. Nossos alunos precisam desenvolver sua capacidade de questionar para compreender o Direito e compreender o mundo em que estão inseridos, sem somente tornarem-se reprodutores daquilo que escutam ou leem nas chamadas da internet.

Zolo (2011, p.16), inclusive, ao tratar sobre o surgimento e consolidação dos direitos de "terceira geração", chama a atenção para a necessidade de reconhecimento do denominado “direito à autonomia cognoscitiva”, “(...) entendida como a capacidade racional de cada sujeito de controlar, filtrar e interpretar as comunicações que recebe” (2011, p.16). Ora, nossos jovens já nascem expostos a uma enxurrada de informações e conhecimentos fragmentados e superficiais, sem que sejam incentivados a, individualmente, construírem sua própria identidade e conhecimento. O direito à autonomia cognoscitiva, bem tratado por Zolo (2011), é uma nova categoria dos direitos humanos que merece ser discutido no meio jurídico. 


\section{O PROFESSOR COMO CHAVE PARA O RESGATE DE NOSSOS ALUNOS}

A descrição acima disposta das nossas salas de aula poderia, num primeiro momento, desestimular o ensino e a aprendizagem jurídica. Todavia, entendemos que tal contexto pode ser revertido pela atuação de sujeitos fundamentais: os professores. Rubem Alves traz uma brilhante metáfora para nos conscientizar disto,

Se os alunos refugam diante da comida e se, uma vez engolida, a comida provoca vômitos e diarréia, isso não quer dizer que os processos digestivos dos alunos estejam doentes. Quer dizer que o cozinheiro - professor - desconhece os segredos do sabor. A educação é uma arte. O educador um artista. Aconselho os professores a aprender seu ofício com as cozinheiras. (ALVES, 2005. P.39)

Dessa forma, conforme bem ensinado por Abreu (1990, p.118), o professor não é responsável somente pelo conteúdo e avaliação, mas também por criar maneiras de se facilitar a aprendizagem do aluno. Ele precisa, portanto, estar atento ao cotidiano de seus alunos, ao contexto que eles vivenciam, procurando adaptar o ensino a tal realidade,

\footnotetext{
“A sala de aula está inserida numa instituição educativa, que por sua vez está filiada a um subsistema educacional, que por seu turno é parte do sistema sociopolíticocultural, econômico e religioso brasileiro que, a seu modo, está vinculado à realidade histórica do Ocidente" (ABREU, 1990, p.125).
}

Ou seja, o professor precisa reconhecer-se como um mediador, que leva seus alunos ao alcance da aprendizagem, esta deve ser sua maior preocupação. Moretto é categórico ao nos informar que o real sucesso é "quando o professor atinge os objetivos de ensinar, oportunizando a aprendizagem significativa de conteúdos relevantes” (Moretto, 2010, p.17).

Sendo assim, na medida em que o professor é o canal de comunicação entre os alunos e o Direito, ele deve provocar nos futuros bacharéis a vontade de buscarem, por si sós, o conhecimento aprofundado da ciência jurídica. E isso não será encontrado nas redes sociais, nos blogs de resumos jurídicos e nas conversas de Iphones.

Mas como exatamente os professores poderiam auxiliar nossos alunos? Quais as metodologias e técnicas a serem adotadas? Na próxima seção traremos algumas estratégias que podem ser adotadas pelos professores de Direito, no intuito de renovar em nossos alunos a curiosidade e o interesse pela ciência jurídica, de modo autônomo e dialético. Afinal, o professor precisa conscientizar-se do papel fundamental em despertar os alunos para a 
relevância de se desenvolverem profissionais com conhecimento e raciocínio jurídicos bem embasados.

\title{
4 ALGUMAS PRÁTICAS A SEREM ADOTADAS PELOS PROFESSORES DE DIREITO
}

Primeiramente, entendemos fundamental a adoção da bibliografia pelos mestres de um modo aprofundado e integral, isto é, exigindo de seus alunos a leitura de livros na sua integralidade, evitando a utilização de fontes fragmentadas de conteúdo como estudo principal, tais como resumos e apostilas. A verificação de leitura pode ser realizada mediante estudos dirigidos, bem como debates dentro de sala de aula.

Além disso, ainda que se adote a aula expositiva - método necessário em vistas de planos de ensino muito extensos - sugerimos que sejam utilizadas aulas expositivas dialógicas, ou seja, que incentivem a participação e posicionamento dos alunos, retirando-os da posição passiva e escondida por detrás dos notebooks,

\footnotetext{
A dimensão dialógica da aula expositiva tem o propósito de transformar essa técnica de ensino em uma atividade geradora tanto da reelaboração de conhecimentos, quanto de sua produção. Adotando-a em sala de aula, o professor estará efetivamente praticando uma educação transformadora (...) (LOPES, 1991, p.45)
}

Madeira traz ainda outros aspectos na aula expositiva a serem observados,

\begin{abstract}
"Dê aulas expositivas curtas, dialogadas, com exemplos (peça exemplos aos alunos), enriquecidas com resultados de pesquisa. Mais que isso, a aula tem que ser elaborada de modo a estar comprometida com a aprendizagem, senão não faz sentido. Você pode até ter escrito a aula, treinado em voz alta, gravado, decorado, mas esforce-se para dar a ela uma característica de espontaneidade." (MADEIRA, 2008, P.21)
\end{abstract}

Além disso, Cunha (1989) traz algumas habilidades a serem desenvolvidas pelos professores, as quais, a nosso ver, também poderiam ser utilizadas no nosso contexto, contribuindo para a compreensão da tecnologia a favor de um conhecimento jurídico embasado e plenamente desenvolvido. 
Em primeiro lugar, Cunha (1989, p.164) nos traz a habilidade de organização do contexto da aula, isto é, explicitar aos alunos qual o objetivo daquele encontro, bem como estatuir quais as fontes em que o aluno poderá aprofundar seu conhecimento. Conseguiríamos, através desta habilidade, chamar a atenção dos alunos para a importância do conteúdo ministrado e da amplitude de bibliografias sobre o tema. Com isso, de imediato já se incentiva a utilização de fontes bibliográficas de maior porte pelos alunos, evitando que recorram a resumos ou anotações esparsas tão somente.

A segunda habilidade tratada por Cunha (1989, p.164) é a de incentivo à participação do aluno. Tal habilidade consiste em estimular que o dicente contribua para o desenvolvimento da aula, trazendo casos e exemplos relacionados à matéria. Com isso, poderíamos desvencilhar nossos estudantes de meras pesquisas na internet que, muitas vezes, resultam num conhecimento vago, para que voltem a si mesmos e à sua realidade, enxergando-os como objeto de estudo. A partir de sua experiência individual, os alunos buscariam suas respostas no Direito.

Tais habilidades se relacionam diretamente com a terceira habilidade, denominada "tratamento da matéria de ensino". Nesta, o professor parte da experiência dos alunos, relacionando a prática com a teoria, as causas com os efeitos jurídicos.

Cunha (1989, p.164) encerra abordando as habilidades de variação de estímulos e do uso da linguagem.

A primeira, no nosso entendimento, seria de grande valia para o objetivo aqui proposto. O professor deve, na sua prática docente, variar as maneiras de instigar o estudo de seus alunos. Sendo assim, a pesquisa sobre determinados temas poderia partir de ferramentas tecnológicas, mas sempre aliadas e alternadas a outras fontes de estudo.

Isto é, pesquisa na internet e em resumos jurídicos poderiam ser aceitas, desde que comparadas a obras doutrinárias de relevância no meio jurídico, atentas ainda às práticas jurisprudenciais brasileiras. Os alunos sentiriam-se motivados a partir de tal variação de estímulos e de fontes.

A habilidade do uso da linguagem, por sua vez, consiste no professor ter clareza nas suas exposições, o que, consequentemente, incentiva em seus alunos o desenvolvimento de sua oratória e argumentação. Argumentos e exposições orais são, certamente, melhor fundamentados quando advindos de estudos conscientes e embasados, mediante discussões e debates frente a frente, sem a colocação de meios tecnológicos entre os participantes. 
Em que pese as desvantagens apontadas por Bauman, causadas pela evolução tecnológica e pela cultura do consumismo, não podemos deixar de resgatar o seu lado positivo. As ferramentas informáticas e as redes sociais podem e devem ser adotadas pelos professores como fontes complementares de conhecimento, criando espaços para a publicação de recentes decisões dos tribunais, para o compartilhamento de interessantes artigos e discussões jurídicas. Os alunos devem compreender referidas tecnologias como algo a mais, como fontes complementares, não como a fonte precípua e única do conhecimento e desenvolvimento da aprendizagem.

Com efeito, conforme bem salienta Abreu (1990, p.6), mais importante que o ensino proporcionado pelos professores, o foco em sala de aula deve ser na aprendizagem do aluno, desenvolvida autonomamente por ele próprio.

(...) se procurarmos decodificar o significado de "ensinar", encontramos verbos como: instruir, fazer saber, comunicar conhecimentos ou habilidades, mostrar, guiar, orientar, dirigir - que apontam para o professor como agente principal e responsável pelo ensino. As atividades centralizam-se no professor, na sua pessoa, nas suas qualidades, nas suas habilidades.

Já quando falamos em "aprender", entendemos: buscar informações, rever a própria experiência, adquirir habilidades, adaptar-se às mudanças, descobrir significados nos seres, fatos e acontecimentos, modificar atitudes e comportamentos - verbos que apontam para o aprendiz como agente principal e responsável pela sua aprendizagem. As atividades estão centradas no aprendiz (aluno), em suas capacidades, possibilidades, oportunidades, condições para que aprenda.

Entendemos que toda e qualquer instituição de ensino, qualquer que seja seu nível, justamente porque existe em função do aluno (pessoa, membro de sua sociedade, profissional) e da sociedade na qual se insere, deverá privilegiar a aprendizagem de seus alunos sobre o ensino de seus professores. (ABREU, 1990, p. 6)

O aluno se torna, portanto, produtor de seu próprio conhecimento, deixando de lado uma postura passiva e acrítica.

\section{CONSIDERAÇÕES FINAIS}

Partindo da teoria baumaniana, verificamos que, infelizmente, a modernidade líquida está presente em grande parte das salas de aula do Direito, já que temos muitos alunos desinteressados em construir o seu conhecimento de modo autônomo e dialético. O cenário é de estudantes que buscam informação e conhecimento superficial e fragmentado. Isso porque a modernidade líquida produz sujeitos que vivem de modo efêmero e acrítico, preocupando-se 
mais em uma busca sem fim de realizar objetivos muitas vezes indefinidos, os quais são descartados de modo cada vez mais ligeiro.

Nesse cenário, os alunos perdem de foco o seu desenvolvimento pessoal na construção de um conhecimento jurídico aprofundado, e assumem uma postura passiva, sem capacidade crítica.

Todavia, o professor, responsável por desafiar seus alunos, mostrando-lhes a relevância do estudo pela melhor doutrina, de modo aprofundado e coerente, é uma saída para resgatas os alunos de tal postura.

É necessário que seja incentivada a capacidade argumentativa e oratória dos graduandos. Para que tais objetivos sejam alcançados, a tecnologia pode ser abordada pelos professores como uma fonte complementar ao estudo, aliada à utilização de aulas expositivas dialógicas, ou seja, que a todo tempo buscam a participação ativa dos alunos.

Ademais, a partir das habilidades apontadas por Cunha (1989) - organização do contexto da aula, incentivo à participação do aluno, tratamento da matéria de ensino, variação de estímulos e uso da linguagem - as quais podem servir de instrumentos para uma construção do conhecimento verdadeiro autonomamente pelos alunos.

A partir da adoção de referidas técnicas, com a atuação contextualizada do professor universitário, poderíamos modificar o atual cenário de posturas passivas e acríticas de grande parte dos alunos de Direito. Para que tudo isso seja colocado em prática, os professores devem estar sempre atentos ao seu papel fundamental na construção e desenvolvimento de seus alunos, como futuros juristas.

Afinal, a ciência jurídica não pode ser reduzida a blogs e apostilas resumidas, privando nossos futuros bacharéis da beleza e amadurecimento trazidos pelo estudo aprofundado e consciente de nossa doutrina e jurisprudência. Como bem nos lembra Rubem Alves, ensinar é uma arte.

\section{REFERÊNCIAS}

ABREU, Maria Célia de. MASETTO, Marcos T. O professor universitário em aula: prática e princípios teóricos. São Paulo: MG Ed. Associados, 1990.

ALVES, Rubens. Entre a ciência e a sapiência: o dilema da educação. São Paulo: Loyola, 2005. 
BAUMAN, Zygmunt. Amor Líquido: sobre a fragilidade dos laços humanos. Rio de Janeiro: Jorge Zahar, 2004.

BAUMAN, Zygmunt. Sobre Educação e Juventude. Rio de Janeiro: Jorge Zahar, 2013.

BAUMAN, Zygmunt. Vida para consumo: a transformação das pessoas em mercadoria. Rio de Janeiro: Editora Zahar, 2008.

CUNHA, Maria Isabel da. O bom professor e sua prática. Campinas: Papirus, 1989. Coleção Magistério: Formação e Trabalho Pedagógico.

FREIRE, Paulo. Ensinar não é transferir conhecimento. Pedagogia da autonomia: saberes necessário à prática educativa. Rio de Janeiro: Paz e Terra, 1999.

LOPES, Antonia Osima, et al. Técnicas de ensino: por que não? Organizado por Ilma Passos Alencastro Veiga. Campinas: Papirus, 1991.

MADEIRA, Miguel Carlos. Sou professor universitário: e agora? Manual de primeira leitura do professor. São Paulo: Sarvier, 2008.

MORETTO, Vasco Pedro. Prova: um momento privilegiado de estudo, não um acerto de contas. Rio de Janeiro; Lamparina, 2010.

ZOLO, Danilo. Rumo ao ocaso global? Os direitos humanos, o medo, a guerra. Organizado por Maria Luiza Alencar Feitosa e Giuseppe Tosi. São Paulo: Conceito Editorial, 2011. 